\author{
Al-Khyatt Muhamad Nadhem, \\ Maksym Skydanenko, \\ Ruslan Ostroha, \\ Anna Neshta, \\ Mykola Yukhymenko, \\ Serhii Yakhnenko, \\ Dmitry Zabitsky, \\ Symeon Yesypchuk, \\ Oleksii Moskalchuk
}

\title{
RESEARCH OF PLATE GRANULATOR OPERATION MODES IN THE PRODUCTION OF COARSE CARBAMIDE GRANULES
}

The object of research is granulation of mineral fertilizers by the rolling method. One of the most problematic places is the uncertainty of the conditions of the temperature regime of granulation. The paper considers the technology for obtaining enlarged urea granules of prolonged action. It is indicated that an increase in the diameter of the granules to 7-10 $\mathrm{mm}$ increases the efficiency of the use of mineral fertilizers by the consumer. It is proposed to obtain large carbamide granules by rolling in a plate granulator. It is indicated that the setting of the optimal operating parameters of the tray granulator is an important factor in the efficient operation of the equipment. A scheme of a pilot plant for granulating mineral fertilizers is presented, a methodology for conducting experimental studies and design parameters of a plate granulator are described. It is indicated that in the process of experimental studies, the design parameters changed: the tilt angle of the plate, the height of the side and the frequency of rotation of the plate, the angle of opening of the spray jet by the hydraulic nozzle. In the process of research, the influence of regime and technological parameters, namely, the temperature of the layer on the plate is studied. As a result of experimental studies, the optimal ranges of design and regime-technological parameters for obtaining enlarged carbamide granules in a plate granulator were revealed. The influence of the location of the nozzle for spraying the melt on the layer relative to the plane of the plate is shown, which results in the particle size distribution of the granular product. It is indicated that a higher content of the commercial fraction in the finished product is observed when the layer in the left sector of the upper part of the plate is irrigated by the rising melt. A technique for determining the static strength of the obtained carbamide granules is given. A calculation equation for determining the static strength of a granule is presented. A diagram of a laboratory device for determining the static strength of granules is presented, which made it possible to determine the values of the static strength of granules for individual fractions, namely: for coarse, fine and commercial fractions. It is shown that the obtained values correlate well with standardized indicators.

Keywords: urea, large granules, run-in granulation, regime and technological parameters, temperature regime, rotational speed.

Nadhem, A.-K. M., Skydanenko, M., Ostroha, R., Neshta, A., Yukhymenko, M., Yakhnenko, S., Zabitsky, D., Yesypchuk, S., Moskalchuk, O. (2022). Research of plate granulator operation modes in the production of coarse carbamide granules. Technology Audit and Production Reserves, 1 (3 (63)), 12-15. doi: http:// doi.org/10.15587/2706-5448.2022.252367

\section{Introduction}

The range of nitrogen fertilizers used in all soil and climatic zones is dominated by urea. This concentrated fertilizer belongs to the category of universal fertilizers, since it is used as the main fertilizer or for top dressing, providing the nitrogen needs of vegetative plants [1]. The main macroelement of this type of fertilizer is nitrogen, which is present in a concentration of at least $46 \%$ (in terms of dry matter) [2].
Along with the well-known advantages, nitrogen fertilizers have significant drawbacks - high solubility in water, increased leaching from the arable layer, which leads to pollution of surface and groundwater. In addition, the use of high doses of fertilizers is often associated with the accumulation of a significant amount of nitrate nitrogen in the main agricultural products, as well as in the soil, which leads to environmental degradation and a decrease in product quality [3].

In this regard, it is extremely necessary to create such forms of nitrogen fertilizers that have a prolonged effect, 
ensuring the efficient use of nitrogen during several cycles of the plant's vegetation. One of the ways to improve efficiency is the use of urea in the form of granules with a diameter of 7-10 mm. According to literature sources [4,5], coarsening the size of the granules of mineral fertilizers used can increase crop yields by $10-30 \%$ (depending on the crop and soil type), while reducing the total nitrogen consumption. This is what determines the relevance of the study.

One of the most common granulation methods is rolling $[6,7]$, due to which granules are formed by aggregation and layering of particles, followed by compaction of their structure. One of the devices for this process is a plate granulator. In this device, it is possible to obtain granules of sufficient strength, the value of which corresponds to the technological standards of use [8]. Plate granulators are simpler in design and more economical than drum granulators, which are currently most often used in the production of granular fertilizers $[9,10]$. For plate granulators, a characteristic feature is the best classifying effect, that is, the separation of granules by size [11]. The strength properties of the obtained granules are influenced by such operating parameters of the process as the rate of spraying of the binder, its concentration, the quantitative supply of powdered retour, the tilt angle and the rotational speed of the plate [12-14]. These studies were obtained for certain process conditions and specific types of material, therefore, they cannot be used to select operating parameters in the case of obtaining coarse carbamide granules. Therefore, the object of research is the process of granulation of mineral fertilizers by the rolling method. The aim of research is to establish the optimal regime and technological parameters of the urea granulation process in a plate granulator.

\section{Research methodology}

The methods of physical modeling of granulation processes by the rolling method were used in the work. When conducting experimental studies, methods of multifactorial planning of the experiment were used. The particle size distribution was determined by sieve analysis. To generalize the experimental data obtained, differential methods of mathematical analysis and integral calculation were used, performed using computer technology and an application package, namely: MathCAD, MS Office Excel.

\section{Research results and discussion}

For research, a laboratory bench was used (Fig. 1), consisting of:

- plate granulator 1 (plate diameter $500 \mathrm{~mm}$, side

height $100 \mathrm{~mm}$ );

- sector dispenser 2;
- hydraulic nozzle 3 with a maximum flow rate of $200 \mathrm{~g} / \mathrm{min}$;

- radiation heater 4 with a power of $15 \mathrm{~kW}$;

- control panel 5 with thermal protection.

The research was carried out in the following way. The carbamide melt (Table 1) with a concentration of more than $92 \%$ is fed directly to the material layer, which is in a heated state on the granulator plate, using a centrifugal nozzle, in which an excess pressure of $0.6-0.9 \mathrm{kgf} / \mathrm{cm}^{2}$ is created. The high temperature of the formation is maintained due to the heat of crystallization of the melt. The granulator plate is rotated by an electric motor at a speed of 15-28 rpm. The design of the granulator allows to change the frequency of rotation of the plate and the tilt angle. The design of the sector dispenser involves changing the recycle feed rate. Electrical appliances were controlled using a control panel with thermal protection. The product grown to a commercial size $(7-10 \mathrm{~mm})$ was rolled over the side of the dish and collected on a special tray for subsequent dispersion.

ig. 1. Pilat plant for mineral fertilizer granulation: 1 - plate granulator; 2 - sector dispenser; 3 - hydraulic nozzle; 4 - radiation heater; 5 - contral panel with thermal protection

Table 1

Characteristics of urea melt

\begin{tabular}{|c|c|}
\hline Parameter & Value \\
\hline${\text { Temperature, }{ }^{\circ} \mathrm{C}}{ }^{-134-140}$ \\
\hline Concentration, $\%$ & $92-99.9$ \\
\hline Melting point (at atmospheric pressure), ${ }^{\circ} \mathrm{C}$ & 132.7 \\
\hline Density, $\mathrm{kg} / \mathrm{m}^{3}$ & $1220-1227$ \\
\hline Melting heat, $\mathrm{kJ} / \mathrm{kg}$ & 241.6 \\
\hline Thermal conductivity, $\mathrm{W} /(\mathrm{m} \cdot \mathrm{K})$ & 0.413 \\
\hline Dynamic viscosity, $\mathrm{mPa} \cdot \mathrm{s}$ & 2.58 \\
\hline
\end{tabular}

Based on the results of the experimental studies, the operating modes of a laboratory plant for granulating carbamide from a highly concentrated melt have been found. It has been experimentally established that lowering the bed temperature below $100^{\circ} \mathrm{C}$ worsens the product quality, causes agglomeration of small particles, and the obtained 
granules also have significant deviations from the spherical shape (Fig. 2).

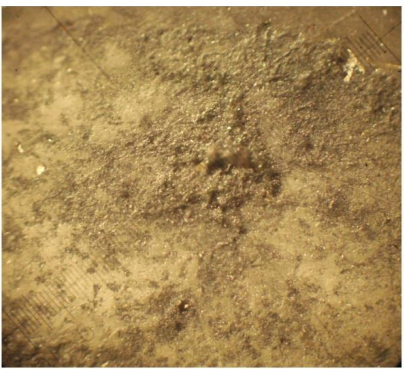

a

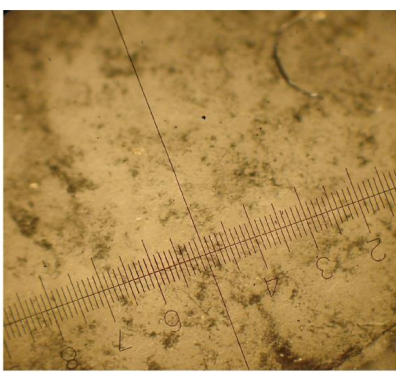

$b$
Fig. 2. Sections of carbamide granules obtained under the appropriate temperature regime of the layer: $a-95-100{ }^{\circ} \mathrm{C} ; b-115-120{ }^{\circ} \mathrm{C}$

The process of carbamide granulation in laboratory conditions has optimal regime and technological characteristics. The operating limits for changing the tilt angle of the plate are $30-60^{\circ}$ with a side height of $100 \mathrm{~mm}$. The optimal tilt angle of the plate when obtaining carbamide granules is $45^{\circ}$, and the temperature of its melt during spraying is $134-140{ }^{\circ} \mathrm{C}$. For a hydraulic nozzle, the spray jet $\beta=65^{\circ}$ is optimal at a pressure in the tank of $0.07-0.09 \mathrm{MPa}$.

Also, a huge role in obtaining a commercial fraction is played by the place where the melt is fed to the granulator plate (Fig. 3).

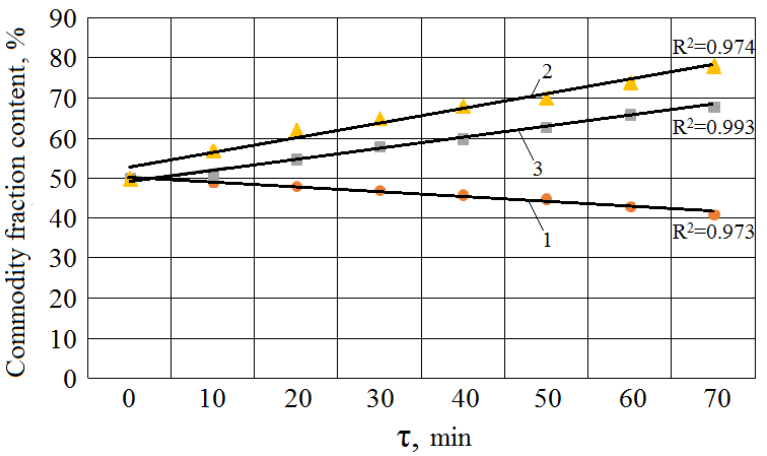

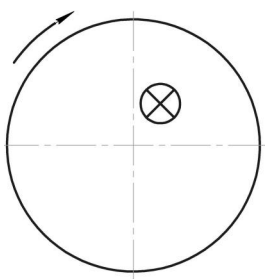

Experiment 1

b

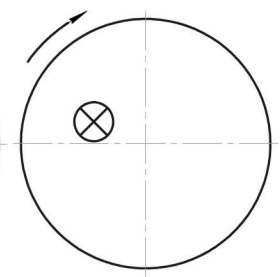

Experiment 2

C

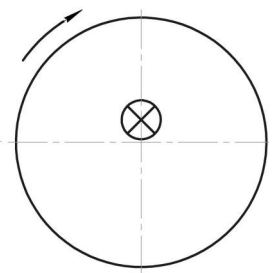

Experiment 3

d
Fig. 3. Dependence of the commercial fraction content in the granular product on the process time for different methods of melt supply: a - graph of the dependence of the commercial fraction content on time; line 1 - when melt is supplied to the upper right sector of the plate; line 2 - when melt is supplied to the upper left sector of the plate; line 3 - when melt is supplied to the central sector of the plate; $b$ - scheme for supplying melt to the upper right sector of the plate; c - scheme for supplying melt to the upper left sector of the plate; $d$ - scheme for supplying melt to the central sector of the plate

The location of the melt spraying zone relative to the plate plane predetermines the granulometric composition of the granulated product. It follows from the graphic dependence (Fig. 3) that a higher content of the commercial fraction in the finished product is observed when the layer in the left sector of the upper part of the plate is sprayed with the rising melt (experiment 2, Fig. 3). This is due to the longer trajectory of the movement of the granules (compared to experiments 1 and 3, Fig. 3) due to the action of rolling friction forces, which causes a longer layering of the material on the surface of the granules and their subsequent strengthening.

Static strength is a very important technological indicator of a granular product. The method for finding the actual value of the static strength of the granules is to determine the boundary force required to destroy the granules of the tested fraction under uniaxial compression between two parallel planes.

The static strength of the granules is calculated by the formula [15]:

$$
X=\frac{\sum_{i=1}^{i=20} P_{i}}{20 \cdot S_{1}}=\frac{\sum_{i=1}^{i=20} P_{i}}{20 \cdot \frac{\pi \cdot D_{A V}{ }^{2}}{4}},
$$

where $P_{i}$ - force required to destroy one granule, N; $S_{1}$ - crosssectional area of the granule, $\mathrm{cm}^{2} ; D_{A V}$ - average diameter of the granules, $\mathrm{cm}$.

Thus, several fractional weights of carbamide granules were selected, which were sequentially destroyed on a laboratory device (Fig. 4) and the critical value of the force was measured on a scale.

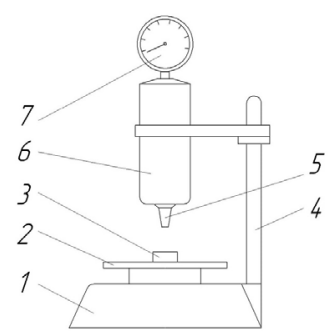

Fig. 4. Scheme of the device for determining the static strength of granules: 1 - base plate; 2 - rotating platform; 3 - adapter; 4 - frame; 5 - probe; 6 - body; 7 - measuring scale

Thus, the static strength of the obtained carbamide granules was: for a fine fraction $-2.1 \mathrm{MPa}$; for the commercial fraction $(7-10 \mathrm{~mm})-1.6 \mathrm{MPa}$; for a large fraction (more than $10 \mathrm{~mm}$ ) $-1.4 \mathrm{MPa}$. The results obtained were compared with standardized values for urea DSTU 7312:2013 (Table 2).

Table 2

Static strength of carbamide granules [2]

\begin{tabular}{|c|c|c|c|c|}
\hline Indicator & $\begin{array}{c}\text { Premium } \\
\text { grade }\end{array}$ & $\begin{array}{c}1 \text { st } \\
\text { grade }\end{array}$ & $\begin{array}{c}\text { 2nd } \\
\text { grade }\end{array}$ & Retail \\
\hline $\begin{array}{l}\text { Static strength of granules, } \\
\mathrm{MPa}\left(\mathrm{kg} / \mathrm{cm}^{2}\right), \text { not less than }\end{array}$ & $1.4(14)$ & $1.2(12)$ & $1.2(12)$ & - \\
\hline
\end{tabular}

It should be noted that the above studies were carried out on an experimental setup with a plate diameter of up to $1 \mathrm{~m}$. Therefore, the uniformity of spraying the material layer with melt and the temperature regime of the layer were maintained by a certain nozzle design and 
a radiative heater. The technical parameters of these elements satisfied the conditions of the experiment, namely, the melt coating of the layer surface and the local action of the heater, the thermal energy of which was sufficient to heat the plate surface layer. But with a large-scale transition to large plate diameters in industrial environments, manufacturers should take this into account and possibly provide for other design approaches, using several (or other types) of nozzles and other sources and devices of thermal energy.

The above study did not take into account the particle size of the retour for the process of rolling the granules, so this issue will be the goal of further research.

\section{Conclusions}

The paper shows that carrying out the process of carbamide granulation in a plate granulator makes it possible to obtain enlarged granules of a commercial fraction of 7-10 mm. Optimal ranges of indicators of design and mode-technological parameters have been obtained:

- the tilt angle of the plate upon receipt is $45^{\circ}$;

- the temperature of the melt during its spraying is $134-140{ }^{\circ} \mathrm{C}$;

- the optimal spray jet for a hydraulic nozzle is $\beta=65^{\circ}$

at a pressure in the tank of $0.07-0.09 \mathrm{MPa}$.

It has been determined that melt spraying should be carried out in the left sector of the upper part of the plate, which leads to a higher content of the commercial fraction in the finished product. The static strength of the commercial fraction is $1.6 \mathrm{MPa}$, which corresponds to the standardized value for carbamide granules.

\section{Acknowledgment}

All the results of the research were achieved within the project «Creation of new granular materials for nuclear fuel and catalysts in the active hydrodynamic environment» (State reg. No. 0120U102036) ordered by the Ministry of Education and Science of Ukraine.

\section{References}

1. Jarchow, M. E., Liebman, M. (2012). Nitrogen fertilization increases diversity and productivity of prairie communities used for bioenergy. GCB Bioenergy, 5 (3), 281-289. doi: http:// doi.org/10.1111/j.1757-1707.2012.01186.x

2. DSTU 7312:2013. Sechovyna (karbamid). Tekhnichni umovy (2013). Kyiv: Minekonomrozvytku Ukrainy, 22.

3. Ostroga, R. A., Iukhimenko, N. P., Mikhailovskii, Ia. E., Litvinenko, A. V. (2016). Technology of producing granular fertilizers on an organic basis. Eastern-European Journal of Enterprise Technologies, 1 (6 (79)), 19-26. doi: http://doi.org/ 10.15587/1729-4061.2016.60314

4. Lisoval, A. P., Makarenko, V. M., Kravchenko, S. M. (2002). Systema zastosuvannia dobryv. Kyiv: Vyshcha shkola, 317.

5. Hospodarenko, H. M. (2003). Ahrokhimiia mineralnykh dobryv. Kyiv: Naukov. svit, 136.

6. Litster, J. D., Ennis, B. J. (2004). The Science and Engineering of Granulation Process. Particle Technology Series. Vol. 15 New York: Springer Science \& Business Media. doi: http:// doi.org/10.1007/978-94-017-0546-2

7. Iveson, S. M., Litster, J. D., Hapgood, K., Ennis, B. J. (2001) Nucleation, growth and breakage phenomena in agitated wet granulation processes: a review. Powder Technology, 117 (1-2), 3-39. doi: http://doi.org/10.1016/s0032-5910(01)00313-8

8. Leszczuk, T. (2014). Evaluation of the Fertilizer Granules Strength Obtained from Plate Granulation with Different
Angle of Granulation Blade. Acta Mechanica et Automatica, 8 (3), 141-145. doi: http://doi.org/10.2478/ama-2014-0025

9. García, L., Rodríguez, G., Orjuela, A. (2021). Study of the pilot-scale pan granulation of zeolite-based molecular sieves. Brazilian Journal of Chemical Engineering, 38 (1), 165-175. doi: http://doi.org/10.1007/s43153-020-00087-x

10. Ouchiyama, N., Tanaka, T. (1981). Kinetic analysis of continuous pan granulation. Possible explanations for conflicting experiments and several indications for practice. Industrial \& Engineering Chemistry Process Design and Development, 20 (2), 340-348. doi: http://doi.org/10.1021/i200013a025

11. Chadwick, P. C., Rough, S. L., Bridgwater, J. (2005). Holdup and Residence Time Distributions in Inclined Dishes. Indus trial \& Engineering Chemistry Research, 44 (19), 7529-7539. doi: http://doi.org/10.1021/ie040252z

12. Azrar, H., Zentar, R., Abriak, N.-E. (2016). The Effect of Granulation Time of the Pan Granulation on the Characteristics of the Aggregates Containing Dunkirk Sediments. Procedia Engineering, 143, 10-17. doi: http://doi.org/10.1016/j.proeng. 2016.06.002

13. Pamungkas, R. B., Jos, B., Djaeni, M., Saputri, K. A. D. (2020). Granulation processing variables on the physical properties of granule slow release urea fertilizer. Proceedings of 2 nd international conference on chemical process and product engineering (ICCPPE) 2019, 2197. doi: http://doi.org/10.1063/1.5140952

14. Przywara, M., Dürr, R., Otto, E., Kienle, A., Antos, D. (2021). Process Behavior and Product Quality in Fertilizer Manufacturing Using Continuous Hopper Transfer Pan Granulation Experimental Investigations. Processes, 9 (8), 1439. doi: http:// doi.org/10.3390/pr9081439

15. GOST 21560.2-82. Udobreniia mineralnye. Metod opredeleniia staticheskoi prochnosti granul (1983). Moscow: Standartinform, 4.

Al-Khyatt Muhamad Nadhem, PhD, Senior Engineer, The General Directorate Education of Iraq, Baghdad, Iraq, ORCID: https:// orcid.org/0000-0003-4284-8125

Maksym Skydanenko, PhD, Senior Lecturer, Department of Chemical Engineering, Sumy State University, Sumy, Ukraine, ORCID: https:// orcid.org/0000-0003-3811-8154

$\triangle$ Ruslan Ostroha, PhD, Department of Chemical Engineering, Sumy State University, Sumy, Ukraine, ORCID: http://orcid.org/00000003-0045-3416, e-mail: r.ostroga@pohnp.sumdu.edu.ua

Anna Neshta, PhD, Department of Manufacturing Engineering, Machines and Tools, Sumy State University, Sumy, Ukraine, ORCID: https:// orcid.org/0000-0003-4072-5439

Mykola Yukhymenko, PhD, Associate Professor, Department of Chemical Engineering, Sumy State University, Sumy, Ukraine, ORCID: http://orcid.org/0000-0002-1405-1269

Serhii Yakhnenko, PhD, Department of Chemical Engineering, Sumy State University, Sumy, Ukraine, ORCID: https://orcid.org/00000003-4386-9059

Dmitry Zabitsky, Cyclic Commission of Specialty «Industrial Machinery Engineering», Professional Machine Building College of Sumy State University, Sumy, Ukraine, ORCID: http://orcid.org/ 0000-0003-4761-0765

Symeon Yesypchuk, Department of Chemical Engineering, Sumy State University, Sumy, Ukraine, ORCID: https://orcid.org/00000002-4101-8827

Oleksii Moskalchuk, Department of Chemical Engineering, Sumy State University, Sumy, Ukraine, ORCID: https://orcid.org/00000002-5773-5775

$\triangle$ Corresponding author 